\title{
Problems and Countermeasures on Children's English Education
}

\author{
Ying Li \\ College of Foreign Languages, Bohai University, Jinzhou, 121013, China \\ 2542572509@qq.com
}

Keywords: Children's English education; problems and countermeasures; quality education

\begin{abstract}
Through extensive research and empirical analysis, summed up the problems existing in the children's English education: education theory is not clear, training target fuzzy, adult children's English teaching, the lack of complete professional English teachers, parents rush mentality, the lack of a real language environment, not suitable for children's English teaching materials. Aiming at the existing problem of children's English education, reference related research results, combined with my years of experience in English education, and puts forward some countermeasures to improve children's English education level, promote the use of activity teaching method, train qualified children's English teacher, write, suited to the characteristics of the children's English teaching materials, play to the role of the emotional guidance, give play to the important role of family education.
\end{abstract}

\section{Introduction}

As domestic of English education, has gradually age had narrowed to learn English from junior middle school began to learn to now before kindergarten began to study primary school. The best time to learn English, academic circles there is no clear conclusion, but based on the theories of second language acquisition, the preschool stage is the important period of learning a language. Some primary school, kindergarten, good conditions and various social training institutions have courses of English, and some learning results have been achieved.

Usually the children English, in 3 to 12 years old children, including the children's English education and children's English test. "Hard not children, then poor education", "can't lose at the starting line" the social popular language has become the consensus of the parents. Every year, more than 100 million people to participate in all kinds of training children among them to accept the number of juvenile's English training proportion is as high as 56\%, far more than other types of early education and training. But because the child is young, mind still relatively immature, inattention, fond play easy to move, this is not a disadvantage more is not a mistake, but children perfectly normal physiological characteristics. If forced to instill a different language to the child, can affect the child's physical and mental health, short of learning effect, and even have a negative impact. In this article, through analyzing the present problems existing in the children's English education in China, the corresponding solutions are put forward, in order to strengthen quality education, promote the comprehensive development of children.

\section{Existing Problems on Children's English Education}

Through extensive research and empirical analysis, summed up the problems existing in the children's English education is as follows:

(1) Education theory is not clear. The children's English education didn't get rid of the thinking mode of English education of primary and secondary schools, many teachers simply to use goal and the methods of English education of primary and secondary schools, the particularity of children's English education has not been seriously, why to teach, what to teach and how to teach, to achieve what goal, the most basic elements of these education theory, has not been clearly defined. Middle and primary school English education theory rich and perfect, but the theory is quite suitable for children's physical and mental characteristics, is scarce. Children's age characteristic, decided to content is easy to forget, don't live with actual use of any English education effect. 
(2) The training target fuzzy. Training target is refers to the education purpose at all levels of the embodiment of all kinds of education institutions. By certain social field and the needs of specific social hierarchy decision, also as accept education object type and level of school. Children's English education has two characteristics: one is to accept the particularity of education main body, is the children. Second, the particularity of education content, education is language. These two special children's English education targets and education process with other education have very big difference. Now to set the children's English education training target is one-sided pursuit of language knowledge, ignore the cultivation of the learning emotion, makes the continuity of the language education severely affected.

(3) Adult children's English teaching. Beautiful childhood innocence and purity is very beneficial for the development of children. But utilitarianism education child died of happiness, the adult standard, teaching material and method of education on children, bear the burden of learning at an early age, thus lost the joy of childhood. Some teachers in children's English teaching, completely ignored the children's psychological characteristics and the characteristics of thinking, from the middle school English class teaching methods, pay attention to the basic knowledge of English teaching, emphasizes the understanding of word meaning, sentence patterns and grammar rules, pay attention to the study of conscious, ignore the unconscious and natural learning, reduced the enthusiasm of children learning English, the child has not really acquire language.

(4) The lack of complete professional teacher of English. It is generally believed that children's English is simple, low demand for teachers. Many teachers without professional training, and don't know the education teaching theory, don't grasp the teaching methods. In fact, eligible children's English teacher must undergo rigorous professional training. To have accurate solid language foundation, concrete consists of reading, listening, pronunciation, speaking, audio-visual, grammar, writing, phrases, sentence patterns and tense, etc.; To be suitable for the high quality of children's English teaching in the new period, and lively personality and develop thinking, good at developing children's interest; Want to children's cognitive development regularity and psychological characteristics have enough understanding, this is the key to the success of teaching. Children's English teacher teaching children language knowledge, at the same time, pays more attention to cultivate their sense of achievement and interest, to make it steady for English learning.

(5) Parents rush mentality. Children's brain and adult brain is the biggest difference between the developing and development of children's brains is a dynamic organization, therefore, to the child's education must be adapted to brain development level. Many parents in children English education aim and get rich quick attitude, despite the child age, and personality differences, one-sided to ask their children to more than other children. Especially when seen around age child to recite words, oral English is better than their children, parents will try to give the child "shake" make up a missed lesson, regardless of the actual situation either well-paid tutor, either for their children to enrol in a variety of crash course in English. Impatient for success is the result of the haste makes waste, the serious influence children's physical and mental health.

(6) The lack of a real language environment. Language environment mainly refers to the language activity depends on factors such as time, occasion and place. On the one hand, language environment is the source of language resources, necessary for learners of language input and influence learner motivation and attitude; On the other hand, for learners learning opportunities and feedback information. Language learning is inseparable from the environment, the lack of language environment, the serious influence language input, and restricts the language learning activities and results. At present domestic is given priority to with juvenile's English training course, in a short time under the environment of Chinese learning English, also can be to develop "deaf English" or "type" exam students.

(7) Not suitable for children's English teaching materials. Teaching is not only a curriculum standard, but also focus on the many experts and scholars of professional wisdom and discipline level, is the essence of knowledge and the crystallization of wisdom. Teaching material is not the general material and books, is according to the purpose of education and students' body and mind law of development and cognitive characteristics, specially developed and written text, suitable for 
the corresponding specific phase of the students' learning. The children's English teaching material sort is more, the quality is uneven, the existence prominent question is: procedural language input, memory burden is too big, weakened the learning motivation; Vocabulary and grammar is difficult, beyond the scope of children's cognitive; The less contextualized language knowledge, language knowledge could not be contextualized into the order of cognitive activity.

\section{Adopted Countermeasures on Children's English Education}

Aiming at the existing problem of children's English education, reference related research results, combined with my years of experience in English education, and puts forward some countermeasures to improve children's English education level is as follows:

\section{(1) Promotion and application of teaching methods}

According to the teaching requirements of the teachers and students the process of acquiring knowledge to provide the appropriate teaching situation, let the students to participate in reading, discussion, games and study operation methods such as knowledge, through the auditory and visual, spatial perception and touch command and collaborative activity in the brain and the acquisition of knowledge. Activity teaching thought and practice is the result of "children's center doctrine" education and "activity curriculum theory", to educational, creative, practical and operable to build children's main body activity as the main form, in order to encourage children's active participation, active exploration and active practice as the basic characteristics, for the purpose of realization of children's comprehensive ability in many aspects. There are many types of activity teaching way, according to the characteristics of children's English teaching, can be divided into three present activities, practice and practice link:

First, present activities. This link is to let children perceive the process of new content for the first time. Teachers design language to present activities, should attract the attention of the children in form, on the content to create appropriate language learning environment for children, around the theme of each unit, the meaning of the new content and use environmental input at the same time, make the child in the context of accurate understanding language materials.

Second, exercise activities. The link is initiated new language project appear designed to train the skills of listening, speaking, reading and writing activities. When a child in the context of real feeling after language and has a certain amount of accumulation, for a lot of practice is very necessary. Children in the perception and understanding of the new content, on the basis of only after much practice, and to achieve a process of memorization and storing.

Third, practice activities. This link is to use what they have learned knowledge of language, in a certain context more aptly express language ability. Language use is the fundamental aim of language learning, the teacher only to provide children a lot of practice to use the language. Try to set up a relatively real language scene, let the child to practice in the language situations.

\section{(2) Cultivate qualified children's English teacher}

Qualified children's English teacher can organize class with a light heart, creates a safe, friendly and harmonious class atmosphere. Qualified children's English teacher, first of all should have the general quality of children's teachers, including three aspects: first, dedication, professionalism is the traditional virtue of Chinese people, spirit is a kind of dedication to work heart and mental state, nature is dedication. Children's teachers to love the cause, love children, responsible for the child, let parents rest assured; The second is, good ethics, ethics is refers to the noble moral character and personality, high sense of responsibility and the dedication to work. Children's teachers to love children, have love will pay. Respect for the child, want to have patience to listen to the opinions of the children, and learn to appreciate. Keep good image, pay attention to your words and deeds, to set an example; Three is, rich knowledge, solve the child's curiosity, let the classroom become rich and colorful, to attract children's attention, let boring knowledge more easily accepted by children.

Children's English teacher must also have abundant professional knowledge. First of all, to understand children's physical and psychological development, the characteristics of children with solid knowledge of pedagogy and psychology as a foreshadowing, understand children's personality and growth rule, understand their needs and interests. Love to play is the nature of children's, adopt 
the game to let the children learn happily. Understanding children's body and mind development regularity and characteristics and pay attention to individual difference according to their aptitude. English teaching method is varied, the different children should take different approaches, including music, children's songs and performances, and other forms; Second, master certain English listening, speaking, reading and writing, because of the children's age is small, just contact with English teacher's guidance, the child's ability to imitate and pick up words ability is very strong, so it is very important to the teacher's words and deeds. Teachers' a mood or an action may affect a child's whole life. Lecture to pay special attention to the change of pronunciation and intonation, the exaggeration and full of voice can make children learn more knowledge.

\section{(3) Write suited to the characteristics of the children's English teaching materials}

Children's English teaching focuses on the cultivation of interest in learning and speaking ability, reading and writing training in a secondary position. Therefore, the teaching material content should strengthen the guide children interest, and does not lie in the depth and breadth of content. Teaching activities as simple as possible, can let the children know how to do; Teaching task can be completed, at the same time, have a strong interest, make the child have a satisfaction and a sense of achievement; Teaching activity is mainly oral, writing practice as far as possible. Textbook writing need to pay attention to the following four points:

First, covering topics should be diversified, as far as possible is closely related to the life, such as family, school, food, travel, animals and plants, and festivals, etc. Genre should also be diverse, such as children's songs, riddles, jokes, essay, and simple and short story. If natural into the teaching activities, the teacher can cause children's interest in learning will get twice the result with half the effort.

Second, pay attention to the principles of communication and interaction, through the creation of life situation, make the child gradually in daily conversation, such as learning greeting, apology, directions, and make a phone call.

Third, in form, a proper selection of multimedia teaching material, teaching lifelike. In order to maintain the child's learning motivation and interest, the difficulty should be moderate, such as vocabulary and sentence structure of the unit should be gradual and from easy to difficult, a review unit, the opportunity to consolidate the language points;

Fourth, we must give attention to both the law of the foreign language learning and memory characteristics of children, try to choose on behalf of the mainstream culture of all kinds of subjects and styles of English article or paragraph, make the child of English national culture and the differences between Chinese and foreign culture have a rough understanding, involves the knowledge of English national culture, should be closely related to students' daily life around and can stimulate the learning interest.

\section{(4) Play the role of emotion guide}

Emotion is the means of English teaching and the purpose of English teaching, plays an inspiring, directional, promote and guide and regulate the role of learning activities, directly affect the students' intelligence development and cognitive process. The strength of emotion in the teaching process and its penetration power directly affect the teaching effect. Children's English learning process as well as other kinds of learning, from shallow interests to the process of deep interest, interest is deeply emotional guidance. Children's English education should follow the principle of quality teaching, improve the teaching of emotional guidance method, and stimulate learning interest and enthusiasm. Specific implementation is divided into three stages:

Primary stage. Emotions to guide and fixing learning foundation. Cultivate emotion, build loose, democratic and harmonious teaching atmosphere. The child's development as the main basis, the teaching process focus on each child's emotions, stimulate interest in learning, help children to establish self-confidence and to use effective learning strategies, enhance the consciousness of the motherland, to exploit international vision, forming a comprehensive language using ability.

Middle stage. With emotions inspire, development language skills. For the children, pay attention to quality education. Special attention to each child's feelings, help them build learning sense of achievement and self-confidence, developing comprehensive language using ability in the 
process of learning, understanding of foreign culture, especially Chinese and western cultural differences, improve humane quality, strengthen the practice ability, training innovation spirit.

Advanced stage, with the emotional constraints, personalized learning achievement. With formative assessment is given priority to, pay attention to cultivate and inspire the enthusiasm of learning and self-confidence, summative assessment focuses on testing integrated language skills and language application ability. Evaluation should promote the development of comprehensive language using ability and healthy personality. Actively carry out extracurricular activities, increase knowledge, widen the vision, intelligence and personality development, talents.

\section{(5) Play an important role of family education}

Family education refers to the parents or elders in the family education of children or adolescents, is an important link of the whole education system, is also a child accept enlightenment phase of education system. Specific measures are as follows:

First, help children establish correct concept of learning English. Family education is the initiation stage of the children accept education system, as the best teacher for children, parents must give their children to set up correct concept of learning English. On the core functions of language communicate and exchanges. To let the children recognize that English is an international common language, in the world occupies an extremely important role in language communication, in order to convenient communication and learning, everyone must learn English.

Second, cultivate their interest in English. Interest is the best teacher. The final effect of children English education depends on whether the child's interest in English was aroused, when the child interested in learning English, will consciously active learning, naive sympathies and twice the result with half the effort. On the one hand, to teach children English, do not be eager to impart knowledge such as dull words and grammar, but combining life random education and inspiration for children; On the other hand, follow the principle of tolerance and encouragement, praise and encourage children, make children in adult stimulate and encourage further intensified activities under interest, forming a virtuous cycle.

Third, build good family learning environment. Language environment is the foundation of learning a language, no language environment, and it is difficult to accurately grasp a foreign language. Post some pictures of English in the room to create language environment; In daily life, let the children grasp common words; Opening the door, get up, eat, sleep, buses, shops and parks scenarios such as English conversation; When foreign friends, encourage dialogue with foreigners; Encouraged to watch CCTV and local TV stations of children's English program, to cultivate good habits of learning English.

\section{References}

[1] Y. Yang, "Problems and countermeasures of children English education in Henan province," Contemporary teaching and research review, vol. 3, no. 3, pp. 128-128, 2015.

[2] S. Liu, "On the strategies of improving children's oral English level," Western China Quality Education, vol. 2, no. 3, pp. 176-176, 2016.

[3] Douban net, "How to carry on children's English family education," https://www.douban.com/note/576955339/, 2016-10-22.

[4] Sina blog, "Children's English: differences in teaching methods and adult education," http://sc.sina.com.cn/edu/cd/zxxpx/2014-09-28/134937754.html, 2016-10-22.

[5] X. L. Li, "Investigation and Research on the present situation of English education for young children," Education Exploration, vol. 28, no. 4, pp. 84-85, 2008.

[6] S. T. Zhou, "Study on the current situation of teachers' professional development in Daqing children's English School," Journal of Language and Literature Studies, vol. 36, no. 2, pp. 133-134, 2016. 